\title{
Analisa Program K3 di CV. Sispra Jaya Logam Dengan Konsep Traffic Light System
}

\author{
Ekie Gilang Permata ${ }^{1}$, M. Eric Ernandes ${ }^{2}$ \\ 1,2 Jurusan Teknik Industri, Fakultas Sains dan Teknologi, UIN Sultan Syarif Kasim Riau \\ Jl. HR. Soebrantas No. 155 Simpang Baru, Panam, Pekanbaru, 28293 \\ Email : ekiegp@yahoo.com
}

\begin{abstract}
ABSTRAK
CV. Sispra Jaya Logam merupakan perusahaan Swasta Nasional yang bergerak dibidang industri pengecoran dan permesinan yang didirikan pada tahun 1992. Dalam proses pengecoran dan permesinan CV. Sispra Jaya Logam mengandung potensi bahaya yang dapat menimbulkan kecelakaan kerja. Hal ini dapat dilihat dari beberapa data kecelakaan kerja yang terjadi dari tahun 2013 sampai tahun 2015 yaitu terjadi 34 kecelakaan. Oleh karena itu penting sekali adanya pencegahan kecelakaan kerja untuk mengurangi risiko kecelakaan sedini mungkin. Pencegahan kecelakaan kerja dapat dilakukan dengan melihat perilaku karyawan terhadap penerapan program K3 (keselamatan dan kesehatan kerja) dan meningkatkan implementasi program K3. Dalam Penelitian Tugas Akhir ini untuk pengukuran tingkat implementasi program K3 yaitu dengan menggunakan Metode Traffic Light System, kemudian dilakukan usulan pembuatan SOP sebagai bentuk implementasi untuk melihat perubahan sikap atau perilaku karyawan terhadap penerapan program K3. Hasil dari kedua analisa diatas dugunakan untuk melihat sejauh mana tingkat implementasi program K3 yang telah dilakukan dan melihat perubahan perilaku karyawan terhadap penerapan program K3.
\end{abstract}

Kata Kunci: Traffic Light System, SOP

\section{Pendahuluan}

Sistem manajemen K3 sebuah hal yang tidak dapat terpisahkan dalam sistem ketenaga kerjaan. Sistem K3 tidak saja sangat penting dalam meningkatkan jaminan sosial dan kesejahteraan para pekerjanya akan tetapi jauh dari itu keselamatan dan kesehatan kerja berdampak positif atas keberlanjutan produktivitas kerja. Data pada CV. Sispra Jaya Logam area produksi masih ada kecelakaan kerja yang terjadi yaitu:

Tabel 1. Data kecelakaan kerja tahun 2013 s/d 2015 di CV. sispra jaya logam

\begin{tabular}{|l|c|c|c|}
\hline Jenis Kecelakaan & $\mathbf{2 0 1 3}$ & $\mathbf{2 0 1 4}$ & $\mathbf{2 0 1 5}$ \\
\hline Ringan & 7 & 8 & 9 \\
\hline Sedang & 2 & 2 & 3 \\
\hline Berat & 2 & - & 1 \\
\hline JUMLAH & 11 & 10 & 13 \\
\hline
\end{tabular}

(Sumber: CV. Sispra Jaya Logam) berikut:

Adapun tujuan penelitian ini adalah sebagai

1. Menghitung kecelakaan kerja di CV. Sispra Jaya Logam pada tahun 2015 .

2. Mengetahui implementasi K3 di CV. Sispra Jaya Logam dengan pendekatan konsep Traffic Light System.
Selanjutnya Batasan masalah dalam penelitian ini adalah sebagai berikut:

1. Penelitian ini hanya pada lantai produksi di CV. Sispra Jaya Logam.

2. Penelitian ini tidak memperhitungkan biaya kecelakaan kerja.

\section{Metodologi Penelitian}

Metodologi penelitian merupakan uraian seluruh kegiatan yang dilaksanakan selama penelitian, Adapun langkah-langkah yang ditempuh dalam penelitian ini adalah 


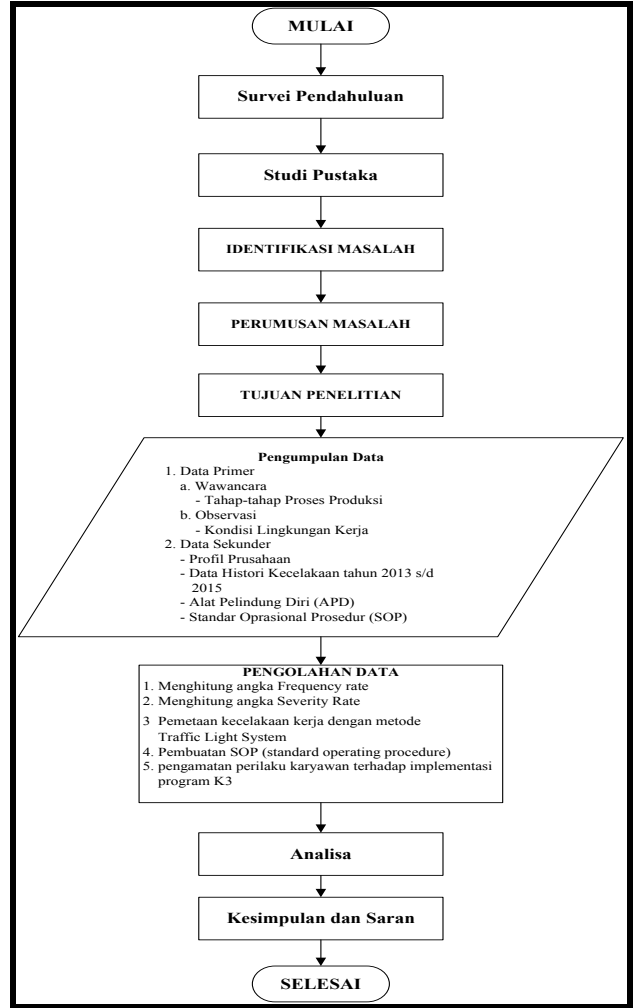

Gambar 1. Flowchart Penelitian

\section{Hasil dan Pembahasan}

Tabel 2. Data kecelakaan kerja tahun 2015

\begin{tabular}{|c|c|c|c|c|}
\hline Bulan & $\begin{array}{c}\text { Sebab } \\
\text { Kecelakaan }\end{array}$ & $\begin{array}{c}\text { Hari } \\
\text { kerja } \\
\text { hilang }\end{array}$ & $\begin{array}{l}\text { Jenis } \\
\text { kecelak } \\
\text { aan }\end{array}$ & $\begin{array}{c}\text { Katego } \\
\text { ri } \\
\text { Kecela } \\
\text { kaan } \\
\end{array}$ \\
\hline Januari & - & - & Ringan & Hijau \\
\hline $\begin{array}{c}\text { Februa } \\
\text { ri }\end{array}$ & - & - & Ringan & Hijau \\
\hline Maret & Tergores & - & Ringan & Hijau \\
\hline April & $\begin{array}{l}\text { Terjepit } \\
\text { besi, } \\
\text { terpukul }\end{array}$ & 4 & Sedang & Sedang \\
\hline Mai & $\begin{array}{l}\text { Terjepit } \\
\text { mesin }\end{array}$ & 8 & Berat & Berat \\
\hline Juni & $\begin{array}{l}\text { Terpukul, } \\
\text { tertimpa } \\
\text { besi }\end{array}$ & - & Ringan & Hijau \\
\hline Juli & - & - & Ringan & Hijau \\
\hline $\begin{array}{c}\text { Agustu } \\
\mathrm{S}\end{array}$ & $\begin{array}{l}\text { Terkena } \\
\text { gram }\end{array}$ & 5 & Sedang & Sedang \\
\hline $\begin{array}{l}\text { Septem } \\
\text { ber }\end{array}$ & $\begin{array}{c}\text { Terpukul, } \\
\text { terkena } \\
\text { benda } \\
\text { panas }\end{array}$ & - & Ringan & Hijau \\
\hline $\begin{array}{c}\text { Oktobe } \\
\mathrm{r}\end{array}$ & - & - & Ringan & Hijau \\
\hline $\begin{array}{c}\text { Novem } \\
\text { ber }\end{array}$ & $\begin{array}{c}\text { Tergores, } \\
\text { tertimpa } \\
\text { besi, } \\
\text { terjepit }\end{array}$ & - & Ringan & Hijau \\
\hline $\begin{array}{c}\text { Desem } \\
\text { ber }\end{array}$ & $\begin{array}{l}\text { Terkena } \\
\text { benda } \\
\text { panas }\end{array}$ & 4 & Sedang & Sedang \\
\hline
\end{tabular}

(Sumber: CV. Sispra Jaya logam)
Perhitungan tingkat kecelakaan kerja pada tahun 2015 adalah

1. Frequency Rate $(\mathrm{F})$

Jumlah karyawan $=17$ orang

Jumlah jam kerja $=8$ jam $\times 6$ jam

$48 \mathrm{jam} / \mathrm{minggu}$

jumlah minggu dalam setahun

52 minggu

Hilangnya hari kerja 21 hari x 8 jam

168 jam

Jam manusia total $17 \times 48 \times 52 \times 168$

7.128 .576

$$
\begin{aligned}
\mathrm{F} & =\frac{\text { Banyaknya kecelakaan } \times 1.000 .000}{\text { Jam manusia total }} \\
& =\frac{13 \times 1.000 .000}{7.128 .576}=1,82 \approx 2 \text { Orang/Jam }
\end{aligned}
$$

2. Saverity Rate (S)

$$
\begin{aligned}
& \mathrm{S}=\frac{\text { Jumlah hari kerja hilang } \times 1.000 .000}{\text { Jam manusia total }} \\
& \mathrm{S}=\frac{21 \times 1.000 .000}{7.128 .576}=2,95 \approx 3 \text { Hari }
\end{aligned}
$$

Pada 2015 kategori kecelakaan paling banyak terjadi masuk kategori HIJAU. Sedangkan tingkat kecelakaan kerja untuk setiap satu juta jam kerja orang yaitu 2 orang korban dan untuk tingkat keparahan total hilang hari kerja pada

\begin{tabular}{|c|c|c|c|}
\hline No & Kategori & Tersedia & $\begin{array}{c}\text { Tidak } \\
\text { tersedia }\end{array}$ \\
\hline \multirow{6}{*}{1} & $\begin{array}{c}\text { Safety } \\
\text { Promotion }\end{array}$ & & \\
\hline & 1. Poster K3 & - & $\checkmark$ \\
\hline & $\begin{array}{ll}\text { 2. } & \text { Majalah } \\
\text { atau Buletin } \\
\text { K3 }\end{array}$ & $\checkmark$ & \\
\hline & $\begin{array}{ll}\text { 3. Kopetensi } \\
\text { K3 } \\
\end{array}$ & - & $\checkmark$ \\
\hline & $\begin{array}{ll}\text { 4. Publisitas } \\
\text { K3 }\end{array}$ & - & \\
\hline & $\begin{array}{ll}\text { 5. } & \text { Pameran } \\
\text { atau Road } \\
\text { show K3 }\end{array}$ & $\checkmark$ & - \\
\hline \multirow{5}{*}{2} & $\begin{array}{c}\text { Safety } \\
\text { Information }\end{array}$ & & \\
\hline & $\begin{array}{ll}\text { 1. } & \text { Sistem } \\
\text { informasi } \\
\text { bahaya K3 }\end{array}$ & - & $\checkmark$ \\
\hline & $\begin{array}{ll}\text { 2. } & \text { Rambu dan } \\
& \text { Label K3 } \\
\end{array}$ & - & $\checkmark$ \\
\hline & $\begin{array}{ll}\text { 3. } & \text { Safety } \\
& \text { handbook }\end{array}$ & $\checkmark$ & - \\
\hline & $\begin{array}{ll}\text { 4. } & \begin{array}{l}\text { Prosedur } \\
\text { meninggalk }\end{array} \\
\end{array}$ & $\checkmark$ & - \\
\hline
\end{tabular}
setiap seribu jam kerja yaitu 3 hari.

Tabel 3. Hasil pencapaian penerapan komunikasi k3 tahun 2015 


\begin{tabular}{|c|c|c|c|}
\hline & $\begin{array}{l}\text { an tempat } \\
\text { kerja }\end{array}$ & & \\
\hline \multirow{3}{*}{3} & $\begin{array}{c}\text { Other form of } \\
\text { consultation } \\
\text { and } \\
\text { communication }\end{array}$ & & \\
\hline & $\begin{array}{l}\text { 1. Safety, } \\
\text { health and } \\
\text { environmen } \\
\text { t briffing }\end{array}$ & - & \\
\hline & $\begin{array}{ll}\text { 2. } & \text { Papan } \\
\text { komukasi } \\
\text { K3 }\end{array}$ & - & $\checkmark$ \\
\hline \multirow{3}{*}{4} & $\begin{array}{c}\text { Emergency } \\
\text { response } \\
\text { procedure }\end{array}$ & & \\
\hline & $\begin{array}{l}\text { 1. Alarm dan } \\
\text { rute } \\
\text { mobilisasi }\end{array}$ & - & $\checkmark$ \\
\hline & $\begin{array}{ll}\text { 2. } & \text { Prosedur } \\
\text { aksi } \\
\text { kegawatdar }\end{array}$ & - & $\checkmark$ \\
\hline
\end{tabular}

\begin{tabular}{|l|c|c|}
\hline \multicolumn{1}{|c|}{ uratan } & & \\
\hline Sub Total & 4 & 9 \\
\hline $\begin{array}{l}\text { Total Bentuk Penerapan } \\
\text { Komunikasi K3 }\end{array}$ & \multicolumn{2}{|c|}{13} \\
\hline Total Pencapaian & \multicolumn{2}{|c|}{4} \\
\hline Persentase Pencapaian & \multicolumn{2}{|c|}{30,76} \\
\hline
\end{tabular}

(Sumber: CV. Sispra Jaya Logam)

Pencapain implementasi program K3 tahun 2015 adalah 30,76\%. Hasil ini menunjukan pencapaian implementasi K3 pada CV. Sispra Jaya Logam pada tahun 2015 terletak pada level MERAH.

Kondisi tingkat kecelakaan pada tahun 2015 terletak pada posisi HIJAU sedangkan tingkat implementasi program K3 pada CV. Sispra Jaya Logam terletak pada posisi MERAH. Hal ini mengidentifikasi bahwa implementasi program $\mathrm{k} 3$ yang telah diterapkan berada keadaan RAWAN

Tabel 4. Pemetaan Tingkat Implementasi-Tingkat Kecelakaan kerja Tahun 2015

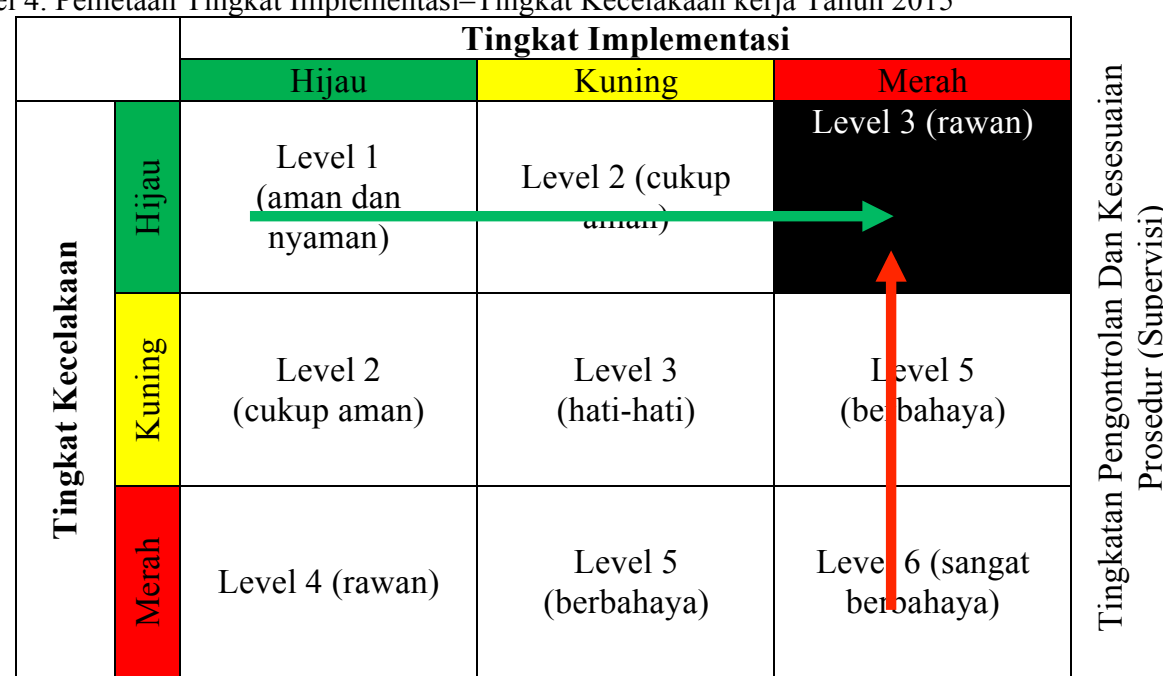

Tabel 5. Rekapitulasi Hasil Kuesioner

\begin{tabular}{|c|l|c|}
\hline No & \multicolumn{1}{|c|}{ Pertanyaan } & $\begin{array}{c}\text { Rata- } \\
\text { rata }\end{array}$ \\
\hline 1. & $\begin{array}{l}\text { Perusahaan berkomitmen } \\
\text { memperbaiki sistem manajemen } \\
\text { K3 }\end{array}$ & 4 \\
\hline 2. & $\begin{array}{l}\text { Perusahaan membuat anggaran } \\
\text { khusus K3 }\end{array}$ & 3,94 \\
\hline 3. & $\begin{array}{l}\text { Perusahaan menyediakan fasilitas } \\
\text { K3 }\end{array}$ & 3,88 \\
\hline 4. & Perusahaan membuat personel K3 & 3,82 \\
\hline 5. & $\begin{array}{l}\text { Perusahaan memelihara fasilitas } \\
\text { K3 yang ada }\end{array}$ & 3,71 \\
\hline 6. & $\begin{array}{l}\text { Perusahaan memberikan sangsi } \\
\text { bagi karyawan yang melanggar } \\
\text { tata tertib K3 }\end{array}$ & 4,12 \\
\hline 7. & $\begin{array}{l}\text { Karyawan ikut andil dalam } \\
\text { pembuatan kebijakan K3 }\end{array}$ & 3,76 \\
\hline 8. & $\begin{array}{l}\text { Saya patuh pada kebijakan K3 } \\
\text { perusahaan }\end{array}$ & 3,76 \\
\hline
\end{tabular}

\begin{tabular}{|c|l|c|}
\hline 9. & $\begin{array}{l}\text { Saya menyadari pentingnya aturan } \\
\text { k3 itu untuk kebaikan saya }\end{array}$ & 4,18 \\
\hline 10. & $\begin{array}{l}\text { Saya akan menjalankan prosedur } \\
\text { K3 walaupun tanpa pengawasan }\end{array}$ & 3,82 \\
\hline Total & 39 & \\
\hline $\begin{array}{c}\text { Rata- } \\
\text { rata }\end{array}$ & 3,90 & \\
\hline
\end{tabular}

(sumber: Data Olahan, 2016)

Berdasarkan hasil kuesioner pada tabel 5 rata-rata responden menjawab 3,90 atau mendekati 4 yang artinya setuju. Hal ini dapat diartikan bahwasanya karyawan setuju dengan program K3 yang diterapkan oleh perusahaan, semakin meningkat program K3 yang dilaksankan oleh perusahaan maka karyawan akan semakin loyal terhadap perusahaan dan akan menjaga performa dan kondisi fisik tetap bugar agar dapat bekerja dengan baik. 


\section{Analisa}

Setelah mendapatkan hasil pengolahan maka langkah selanjutnya adalah menganalisa terhadap hasil pengolahan tersebut. Analisa dilakukan terhadap hasil dari setiap langkah perhitungan data.

1. Berdasarkan hasil pengolahan data padababsebelumya di ketahui bahwa pada tahun 2013 telah terjadi 11 kasus kecelakaan yang mengakibatkan 2 orang korban dan 3 hari hilang hari kerja untuk 1.000.000 jam kerja orang, dan pada tahun 2014 terjadi 10 kasus kecelakaan yang mengakibatkan 3 orang dan 3 hari hilang hari kerja untuk 1.000.000 jam kerja orang, sedangkan pada tahun 2015 terjadi 13 kasus kecelakaan yang mengakibatkan 2 orang dan 3 hari hilang hari kerja untu 1.000.000 jam kerja orang. Untuk lebih jelasnya dapat dilihat pada gambar 2 .

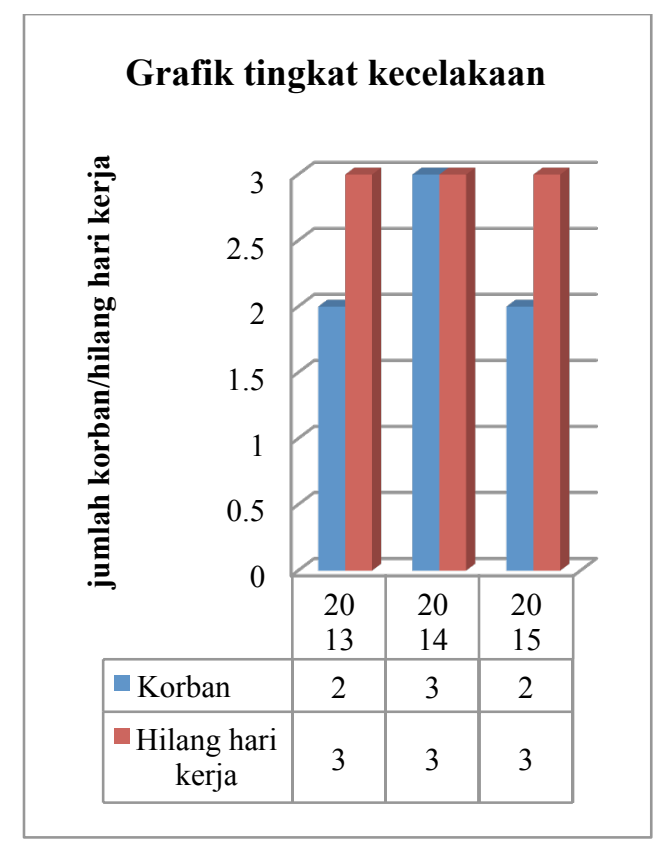

Gambar 2. Grafik tingkat kecelakaan

Pada tahun 2013 tingkat implementasi program keselamatan dan kesehatan kerja (K3) sebanyak 23,07 \% yaitu terletak pada posisi merah dan jumlah kecelakaan dalam katagori hijau, sehingga pada tahun 2013 kondisi traffic light system terletak pada kondisi RAWAN, dan tahun 2014 tingkat implementasi program keselamatan dan kesehatan kerja (K3) sebanyak $15,38 \%$ yaitu terletak pada posisi merah dan jumlah kecelakaan dalam katagori hijau, sehingga pada tahun 2014 kondisi traffic light system terletak pada kondisi RAWAN, sedangkan pada dan tahun 2015 tingkat implementasi program keselamatan dan kesehatan kerja (K3) sebanyak $30,76 \%$ yaitu terletak pada posisi merah dan jumlah kecelakaan dalam katagori hijau, sehingga pada tahun 2013 kondisi traffic light system terletak pada kondisi RAWAN.

Dari tingkat kecelakaan kerja yang paling tinggi yaitu pada tahun 2014 yaitu 3 orang korban dan 3 hari hilang hari kerja untuk 1.000.000 jam kerja manusia, sehingga dapat diketahui bahwa tingkat implementasi program K3 berbanding lurus dengan tingkat kecelakaan, dapat dilihat pada kasus kecelakaan kerja pada tahun 2015 terjadi penurunan yaitu 2 orang korban dan 3 hari hilang hari kerja untuk 1.000.000 jam kerja manusia, seharusnya pihak manajemen CV. Sispra Jaya Logam melakukan tindakan peningkatan implementasi, pencegahan, investigasi dan perbaikan pada program keselamatan kerja. Hal ini dapat dilakukan untuk meminimalisir kasus risiko kecelakaan kerja pada tahun selanjutnya sehingga angka kecelakaan dari tahun ketahun semakin menurun menjadi zero accident.

2. Pembuatah usulan SOP (standard operating procedure) adalah bentuk implementasi dari peneliti untuk mengetahui perubahan perilaku karyawan terhadap pandangan keselamatan dan kesehatan kerja (K3) dan untuk melihat perubahan perilaku karyawan peneliti menyebarkan kuesioner terhadap karyawan, dari hasil yang telah dilakukan data yang diperoleh atau semua item intrumen valid karena $\mathrm{r}$ hitung $>\mathrm{r}$ tabel, dengan $\mathrm{r}$ tabel sebesar 0,4821. Uji validitas dilakukan untuk mengetahui pemahaman responden terhadap pertayanan yang diberikan. Setelah dilakukan uji validitas dn di teruskan dengan uji reliabilitas, uji reliabilitas dilakukan untuk melihat keandalan pertanyaan, apakah kuesioner dapat digunakan kembali setidaknya oleh responden yang sama dan menghasilkan data yang konsisten. Dari hasil reliabilitas nilai cronbach's alphasebesar 0,761 yang artinya hubunganerat dan reliabel.

Dari hasil implementasi program K3 dan kedua uji menunjukkan bahwa karyawan atau pekerja suatu perusahaan (CV. Sispra Jaya Logam) memiliki hubungan yang searah dengan program K3 yang telah dilakukan atau Balance. Semakin baik program K3 yang diberikan perusahaan, maka karyawan akan menjaga kinerja atau menjaga kondisi kesehatan karyawan tersebut. 
Tabel 6.Tabel Tingkat pengontrolan

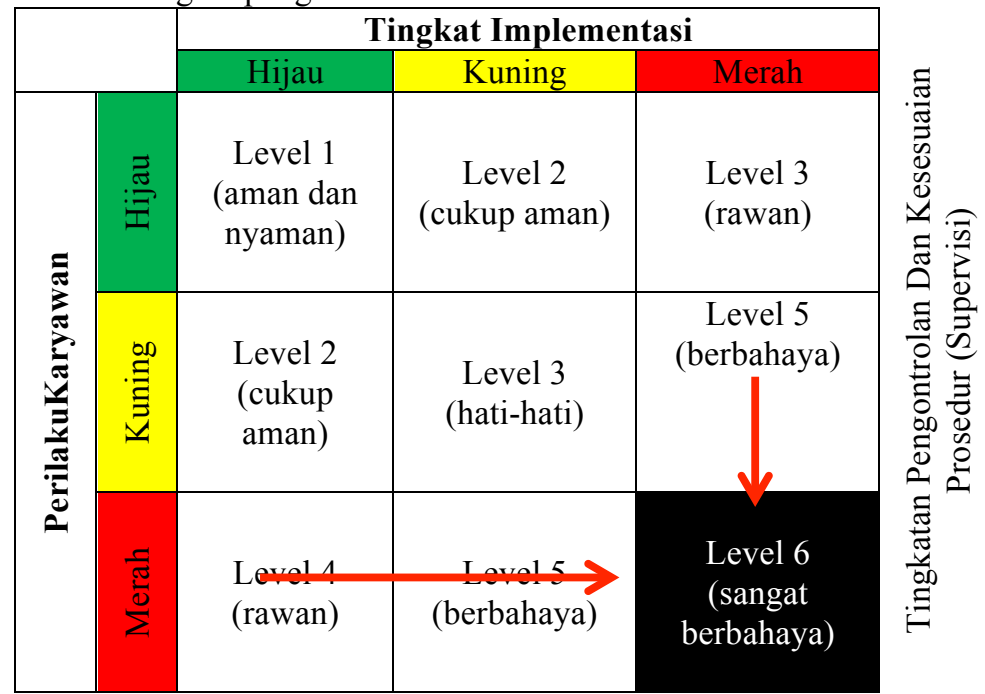

Dapat dilihat pada tabel dan gambar di atas perilaku karyawan berhubungan erat terhadap implementasi perusahaan, untuk merubah perilaku karyawan tidaklah gampang karena bersangkutan dengan sifat dasar manusia itu sendiri, tetapi untuk meningkatkan perilaku agar lebih baik lagi, perusahaan harus member sangsi tegas terhadap karyawan yang melanggar aturan K3 perusahaan (DIPAKSA), setelah itu karyawan akan TERPAKSA sedikit demi sedikit akan merubah perilaku terhadap pandangan K3, setelah terpaksa lama-lama karyawan akan TERBIASA dengan apa yang telah dilakukannya, karena karyawan akan berfikir hal yang biasa dilakukan jika ditinggalkan akan merasa ganjal atau ada yang kurang saat bekerja setelah semua terjalankan maka BUDAYA kan perilaku aman saat bekerja.

\section{Kesimpulan dan saran}

Berdasarkan hasil penelitian yang dilakukan di lantai produksi CV. Sispra Jaya Logam, maka secara umum dapat disimpulkan sebagai berikut:

1. Tingkat kecelakaan kerja yang terjadi pada pada 2015 menunjukan nilai Frequency Rate dan Saverity Rateatau tingkat kekerapan kecelakaan 2 orang korban dan 4 hari hilang hari kerja untuk 1.000.000 jam kerja manusia.

2. Untuk tingkat implementasi dan tingkat kecelakaan pada tahun 2015 dalam kondisi Rawan, ini dikarenakan tingkat implementasi program K3 pada lantai produksi CV. Sispra Jaya Logam belum mencapai $60 \%$, karena indikator implementasi K3 masih dibawah $60 \%$ sehingga implementasi program K3 masuk dalam posisi Merah.
3. Hubungan antara sikap karyawan terhadap penerapan program K3 berjalan searah, semakin baik penerapan program K3 yang dilakukan oleh perusahaan maka sikap karyawan akan ikut membaik untuk menjaga performa dan menjaga kondisi fisik agar dapat terus bekerja.

4. Usulan SOP yang diberikan oleh peneliti pada lantai produksi yaitu berupa SOP-SOP proses kerja seperti proses pembubutan, proses skrap, proses fabrikasi dan proses pengecoran logam.

Saran yang diberikan dalam laporan penelitian ini untuk pihak perusahaan CV. Sispra Jaya Logam adalah:

1. Perlu adanya peningkatan pembinaan dan pelatihan K3 mengenai sikap kerja, cara kerja, potensi bahaya dan faktor bahaya yang mungkin timbul pada setiap aktivitas yang ada.

2. Perlu adanya pengawasan dan pengarahan yang ketat dari perusahaan tentang penggunaan alat pelindung diri (APD) dan adanya sanksi yang lebih tegas bagi pelanggar serta bila perlu dibuat peraturan khusus mengenai hal tersebut.

3. Ada baiknya sarana rambu-rambu keselamatan kerja dibuat jelas, mudah dilihat dan mudah dipahami pada daerah-daerah yang rawan terjadi kecelakaan.

\section{Daftar Pustaka}

[1] Buntarto. "Panduan Praktis Keselamatan dan Kesehatan Kerja untuk Industri”, Penerbit Pustaka Baru Press, 2015 
[2] Daryanto. "Keselamatan Kerja Peralatan Bengkel dan Perawatan Mesin", Penerbit Alfabeta, Bandung, 2010

[3] Peraturan Menteri Tenaga Kerja Dan Transmigrasi Republik Indonesia Nomor PER.08/MEN/VII/2010 Tentang Alat Pelindung Diri

[4] Ramli, S. "Sistem Manajemen Keselamatan dan Kesehatan Kerja OHSAS 18001", Penerbit Dian Rakyat, 2010

[5] Sucipto, Dani. C. "Keselamatan dan Kesehatan Kerja", Penerbit Gosyen Publishing, 2014

[6] Suma'mur. "Keselamatan Kerja dan Pencegahan kecelakaan", Penerbit Yayasan Masagung, 1989 